\title{
Weight Gain, Obesity, and Psychotropic Prescribing
}

\author{
Nikhil Nihalani, ${ }^{1}$ Thomas L. Schwartz, ${ }^{2}$ Umar A. Siddiqui, ${ }^{3}$ and James L. Megna ${ }^{4}$ \\ ${ }^{1}$ SUNY Upstate Medical University, Syracuse, NY 13210, USA \\ ${ }^{2}$ Department of Psychiatry, SUNY Upstate Medical University, 750 East Adams Street, Syracuse, NY 13210, USA \\ ${ }^{3}$ Depression and Anxiety Disorders Research Program, Department of Psychiatry, SUNY Upstate Medical University, Syracuse, \\ NY 13210, USA \\ ${ }^{4}$ Departments of Psychiatry and Medicine, SUNY Upstate Medical University, Syracuse, NY 13210, USA
}

Correspondence should be addressed to Thomas L. Schwartz, schwartzresearch1@yahoo.com

Received 15 June 2010; Revised 25 November 2010; Accepted 9 December 2010

Academic Editor: S. B. Heymsfield

Copyright (C) 2011 Nikhil Nihalani et al. This is an open access article distributed under the Creative Commons Attribution License, which permits unrestricted use, distribution, and reproduction in any medium, provided the original work is properly cited.

\begin{abstract}
A majority of psychiatric medications are known to generate weight gain and ultimately obesity in some patients. There is much speculation about the prevalence of weight gain and the degree of weight gain during acute and longitudinal treatment with these agents. There is newer literature looking at the etiology of this weight gain and the potential treatments being used to alleviate this side effect. The authors undertook a comprehensive literature review in order to present epidemiology, etiology, and treatment options of weight gain associated with antipsychotics, mood stabilizers, and antidepressants.
\end{abstract}

\section{Introduction}

Weight gain is a major health problem in the United States and is a common adverse effect associated with many psychiatric drugs used to treat depression, anxiety, bipolar disorder, and schizophrenia. Clearly the new, second generation antipsychotics have gathered much press and literature about thier profound effects on weight gain and the development of metabolic disorders. Class action law suits have been filed and settled against drug manufacturers, and the FDA has issued cautions about these serious side effects with this class of medications. Psychiatric prescribers are well aware of this side effect profile of antipsychotics but also note weight gain to be associated with a majority of other commonly used psychiatric medications.

Induction of weight gain and obesity often contributes towards psychotropic medication nonadherence. This can lead to relapse and hospitalization. Weight gain clearly contributes to medical comorbidity $[1,2]$. Currently prescribed psychotropics (antipsychotics, antidepressants, and mood stabilizers) may cause $2-17 \mathrm{~kg}$ of weight gain over the course of clinical treatment [3-6]. Unfortunately, there are only a very few psychotropics associated with weight loss [7-9]. This paper will briefly review the epidemiology, possible etiology, and available treatment options for psychotropicinduced weight changes. In a novel format, the authors will present brief clinical cases to help convey information about typical patient scenarios and management strategies.

\section{Weight Gain due to Psychotropics}

Case 1. HA is a 22-year-old female suffering from depressive disorder and social anxiety disorder. She had failed to respond to an initial SSRI antidepressant (paroxetine) and was subsequently placed on an SNRI. She had a partial response to this agent and developed a minimal $1-2 \mathrm{~kg}$ weight gain. An approved second generation antipsychotic (aripiprazole) was added for her resistant symptoms and after 6 weeks of treatment she experienced a $5 \mathrm{~kg}$ weight gain.

The above case is a typical and common example of iatrogenically induced weight gain. With the introduction of the newer, atypical second generation antipsychotics (SGAs), the potential to cause remarkable weight gain has been recognized. Nearly every antipsychotic has been reported to cause weight gain. Although comparison is limited by the different designs and recruitment procedures of reviewed studies [10], a MEDLINE search from 1966 
to 2009 showed that the amount of body weight gain was highest in patients treated with olanzapine (average body weight gain $2.3 \mathrm{~kg} /$ month), quetiapine (1.8 kg/month), and clozapine $(1.7 \mathrm{~kg} / \mathrm{month})$. Treatment with risperidone showed moderate changes in body weight (average body weight gain $1.0 \mathrm{~kg} /$ month), where ziprasidone seemed to induce only slight body weight changes $(0.8 \mathrm{~kg} / \mathrm{month})$. Asenapine causes up to $0.9 \mathrm{~kg}$ weight gain in the first three weeks of treatment [11] and its FDA Package Insert discusses a 52-week regulatory trial causing negligible weight gain over time, suggesting it may also be less metabolically problematic [12]. Nineteen percent of patients treated with asenapine have weight gain as compared to $31 \%$ who were treated with olanzapine [13]. The other recently FDA approved second generation antipsychotic is iloperidone. It has shown mild to moderate weight gain $(1.5-2.1 \mathrm{~kg})$. This appears to be more than that produced by ziprasidone, but more similar to that seen with risperidone [14]. The above two antipsychotic medications may not have enough postmarketing data available as of now to clearly delineate weight gain potential. Paliperidone was approved a few years back, and both shortand long-term (52 weeks) studies have shown no significant metabolic side effects including weight gain $[15,16]$. The weight gain associated with paliperidone could, in theory, be similar to risperidone as it is an active risperidone metabolite, unless the parent drug contains the weight-inducing components which are now omitted from the paliperidone pharmacodynamic profile after liver first-pass metabolism.

A common comparative finding in the literature suggests that risperdone causes weight gain between $0.3-2.6 \mathrm{~kg}$ while ziprasidone often causes weight loss [17-26]. Olanzapine may be the most significant second generation agent causing weight gain from $4.2-7.4 \mathrm{~kg}$, and even up to an average gain of $12 \mathrm{~kg}$ in $45-90 \%$ of patients [27-32]. Quetiapine (regular release and extended release) also has been implicated in causing a more remarkable weight gain of 4.1 to $5.6 \mathrm{~kg}$ $[33,34]$. Clozapine may ultimately be the most likely agent to cause weight gain of all psychotropics producing increases of 2.4 to $31.3 \mathrm{~kg}$, which is often a 10 percent gain over baseline [35-39]. Finally, a short-term study using aripiprazole showed a limited, $0.5-0.9 \mathrm{~kg}$ weight gain as compared to placebo [40].

Case 2. SK is a 43-year-old female with depressive disorder and posttraumatic stress disorder. She failed to respond to an approved SSRI (sertraline) but experienced minimal weight gain. She was placed next on a combination of an SNRI (venlafaxineER) and a dopamine-norepinephrine reupake inhibitor (bupropionSR) also without symptomatic improvement. She did not gain weight. Given her treatment resistant symptoms, she was placed on tricyclic antidepressants (imipramine, nortriptyline) with a minimum of weight gain but experienced cardiac side effects. Finally, she was placed on an MAOi (tranylcypromine) with partial symptom improvement, but also a $15-20 \mathrm{~kg}$ weight gain. She developed social anxiety and agoraphobia, almost refusing to go out of her house due to the excessive weight gain.

The prevalence of weight gain due to antidepressants such as imipramine (causing a $3-4 \mathrm{~kg}$ weight gain) is more chronic and more common, yet underrecognized as depression and anxiety are more prevalent diagnostically and epidemiologically as compared to psychotic disorders [41].

Tricyclic antidepressants (TCAs) and perhaps monoamine oxidase inhibitors (MAOIs) may be more likely to cause weight gain than the selective serotonin reuptake inhibitors (SSRIs), while mirtazapine may be placed between the SSRIs and the TCAs in terms of relative risk of weight gain $[42,43]$. Bupropion may be the only modern agent that lowers weight [5]. There is a $1-3 \mathrm{~kg}$ average weight gain on antidepressants in 10-20\% of the population treated with them (likely a mixture of serotonergic facilitation (excess synaptic serotonin, may downregulate and desensitize serotonin-2c receptors causing increased appetite) and anticholinergic properties). This is further complicated by the fact that antipsychotic medication use is escalating after FDA approval for bipolar and major depressive disorders, which may most likely increase the incidence of metabolic effects. MAOI's use results in moderate weight gain [6]. Trazodone studies show 0.5 to $1.1 \mathrm{~kg}$ weight gain over time $[8,44]$, while five percent of baseline weight loss or $3-4.4 \mathrm{~kg}$ of weight loss has been reported with bupropion [45-47]. Although initial studies showed weight loss with fluoxetine, long-term followup reveals that its weight reducing effect is associated with a gain in body weight developing over time [48]. Acute losses of $0.35 \mathrm{~kg}$ may be noted, but an average of $2-2.5 \mathrm{~kg}$ of weight may be gained [49]. Citalopram may cause 1 to $1.5 \mathrm{~kg}$ weight gain over a year's time $[50,51]$. Fluvoxamine $[5,52]$ has two studies showing no weight gain and no weight loss. Sertraline studies suggest more weight gain than control groups [53]. Paroxetine is the most likely of the SSRIs to cause weight gain. Tohen et al. showed that paroxetine promoted more weight gain when compared to fluoxetine and sertraline [53]. These findings suggest a lesser iatrogenic weight gain side effect profile compared to the SGAs mentioned above.

Mirtazapine has consistently shown greater weight gain when compared to SSRIs (fluoxetine, paroxetine, and citalopram) [54-56]. In clinical practice it seems to react like an SGA in this regard. However, aripiprazole which has recently been approved for adjunctive treatment of major depressive disorder, differs as it tends to have a lower risk of association with metabolic abnormalities [57]. In some patients though, the use of aripirpazole as an adjunct may contribute to a higher likelihood of weight gain [58]. As far as the newer SNRI duloxetine is concerned, in a recent 8 month double blind randomized prospective trial with subjects initially on duloxetine, escitalopram or placebo, the mean change in weight was significantly higher for escitalopram compared with duloxetine $(+0.61 \mathrm{~kg}$, duloxetine; $+1.83 \mathrm{~kg}$, escitalopram; $P<.05)$. However, the incidence of treatmentemergent abnormal weight gain (FDA definition suggests greater than or equal to a $7 \%$ increase in weight from baseline) was similar between drugs and was significantly greater for both duloxetine and escitalopram compared with placebo. Mood stabilizing agents are used for bipolar disorder and schizoaffective disorder. As with the antipsychotics and antidepressants, weight gain is a common side effect. 
Seventy-one percent of divalproex treated patients may gain more than $4 \mathrm{~kg}$ [6]. Nine tenths of a kilogram to fourteen kilogram of divalproex-induced weight gain has been reported in other studies $[59,60]$ with an incidence of $8-59 \%$. Lamotrigine has a more favorable, weight neutral profile and may cause weight loss (of $2 \mathrm{~kg}$ ) or a gain (up to $0.6 \mathrm{~kg}$ ) [61]. Carbamazapine may show a weight change up to $15 \mathrm{~kg}$ based on limited studies $[62,63]$. Lithium reviews suggest that weight gain is also a common side effect. Twenty percent of patients on lithium gained $10 \mathrm{~kg}$ or more in one study and a $6.3 \mathrm{~kg}$ weight gain in a second [64].

\section{Cause of Weight Gain}

This section will attempt to briefly review the possible causes of iatrogenic weight gain. Gothelf et al. [65] studied weight gain mechanisms and energy balance in olanzapine-treated adolescent male patients and found that an increase in body mass index was due to an increase in calorie intake, but also revealed effects on the resting energy expenditure or slowing of metabolism. Psychotropics have broad pharmacodynamic profiles, and it is likely that multiple neurotransmitters, receptors, and neurocircuits are responsible for drug-induced weight gain. Olanzapine has activity at several different receptor sites [66]. Others, like clozapine, may act at even different receptors (i.e., $\delta$-opiod receptors) [67]. In rats, activating $5-\mathrm{HT}_{2 \mathrm{C}}$ receptors decreases eating behavior and mice lacking $5-\mathrm{HT}_{2 \mathrm{C}}$ receptors become obese [68]. Many of the antipsychotics (olanzapine, quetiapine, and clozapine) and some antidepressants (mirtazapine) have this $5-\mathrm{HT}_{2 \mathrm{C}}$ blocking property.

Beta-3 adrenergic receptors found in adipose tissue play an active role in weight control by converting fat into energy especially in response to norepinepherine [69]. Clinically there are no data to suggest effects on weight gain with alphaadrenoceptor antagonists but it is known that psychotropics with higher affinities (i.e., TCAs) for these receptors are associated with weight gain, whereas those with lower affinities (e.g., SSRI) are not [70]. Psychotropics with greater ability to block $\mathrm{H}-1$ receptors often show greater weight gain potential [71], possibly through deactivating brain satiety centers. Another mechanism may be related to blockage of anticholinergic sites, which is associated with appetite stimulation.

\section{Treatment Weight Gain}

Potential weight loss strategies are outlined in Table 1. Early intervention is the key to preventing significant drug-related weight gain. Patients should be educated about weight gain as a potential adverse effect before they begin treatment and their weight should be monitored routinely as a standard of care, as long as they continue taking drugs that may increase weight. Informed consent about this risk should be the standard of care. Routine blood and vital sign monitoring for detection of increases in blood sugars, serum lipids, blood pressure, and abdominal girth would be helpful and clinically warranted [72].
Metabolic syndrome is now a well-documented effect of second-generation antipsychotic use. Ideally, a diet and exercise plan should be initiated to prevent or treat weight gain before medically significant weight gain occurs [73]. A successful weight loss program is one which can produce a loss of 0.5 to $1 \mathrm{lb}$ of the patient's initial body weight per week, a rate of loss considered safe and acceptable [74]. Diet and exercise produces maximal benefit, but requires considerable commitment and motivation on the part of the patient. This is often difficult or impossible in the mentally ill.

Case 1: Part 2. HA had been given informed consent prior to starting her serotonergic antidepressants about the potential for weight gain and was advised to consider prophylactically increasing her current low level exercise regimen, to watch caloric intake, and to weigh herself with directions to notify the clinician if she experienced a consistent gain of 2.5 or more kilograms. After mild initial weight gain, dieting by portion control methods was discussed. After a more remarkable weight gain was noted with the second generation antipsychotic, she was offered off-label use of chromium picolinate, or metformin, or approved use of orlistat. The patient felt chromium picolinate had the most favorable risk profile and tried $1000 \mathrm{mcg}$ daily without weight improvement. At a subsequent visit she was placed on metformin. (These interventions are discussed later in this paper).

Case 3. $\mathrm{AB}$ is a 30 -year-old female with depression, anxiety, and substance use disorder. Despite gaining sobriety, she still suffered depressive symptoms and failed to respond to initial SSRI (fluoxetine) and SNRI (duloxetine) therapy. She was placed on the second generation antipsychotic, quetiapine, with moderate symptom reduction but began to gain weight (3-5 kg) and asked for other treatment options. She was cross-titrated onto aripiprazole with an acceptable weight loss as a result and continued symptom reduction.

Besides diet and exercise, formal behavior modification techniques involve changing eating habits and reinforcing desired weight controlling behavior. It is the gradual but consistent change in behavior that leads to healthier eating habits. Simple use of portion control behaviors can teach patients to eat less at every meal without the complexity of counting fat versus carbohydrate calories, and does not require the willpower to follow a bland low-salt, low-fat, lowsugar diet [75]. Behavior modification alone can generate a weight loss of $0.5 \mathrm{~kg}$ to $0.7 \mathrm{~kg}$ per week [76]. Through formal, manualized cognitive-behavioral therapy patients can achieve satisfaction with body image and acceptance of modest weight loss. In one study, the effects of cognitivebehavioral therapy on weight gain due to psychotropics was studied in 6 schizophrenia patients (mean age 37.3 years). The mean BMI $\left(\mathrm{kg} / \mathrm{m}^{2}\right)$ decreased from $29.6 \mathrm{~kg}$ to $25.1 \mathrm{~kg}$ in the posttreatment group [77]. Cognitive therapy has been helpful in reducing weight for children and adolescents [78]. Furthermore, the addition of cognitive therapy to a dietcontrolled method produces better results [79].

Generally, drug therapy with specific metabolic informed consent, active monitoring of weight and early intervention, 
or even prophlyaxis with diet and exercise are the first treatment options. If this fails, or the patient is too ill to comply, then clinical practice suggests that antiobesity drugs may be appropriate. Risks and benefits should be evaluated for each antiobesity agent. Sometimes, prior to trying an antiobesity medication, one may choose to switch the current psychotropic medication to one with the same indication but less weight gain potential as noted in the case above. The risks and benefits of changing an effective medication should be adequately considered before making changes.

Chromium compounds were utilized in a case above and have been used over the counter to facilitate weight loss, although the evidence for its efficacy is lacking so far [80, 81]. However, chromium picolinate has reasonable data in regards to improving insulin sensitivity in diabetics and has been shown to help curb carbohydrate cravings in depressed patients despite continued depressive symptoms when dosed $600 \mathrm{mcg} / \mathrm{d}[82,83]$.

Drugs that reduce caloric intake or suppress hunger, are commonly known as anorectic agents or appetite suppressants. They act centrally by decreasing appetite or increasing satiety. Sympathomimetic agents include phendimetrazine, phentermine, mazindol, diethylpropion (many are controlled substances), amphetamine and related compounds, and phenylpropanolamine. The amphetamine products are used on-label for the treatment of sleep apnea, narcolepsy, and attention deficit/hyperactivity disorders. When these conditions are comorbid with other primary psychiatric disorders a weight loss advantage is often clinically noted. Of note, however, the serotonergic agents, fenfluramine and dexfenfluramine were withdrawn from the US market in September 1997 over concerns about valvular heart disease [84].

The three most currently prescribed drugs that are FDA approved to treat obesity are phentermine, sibutramine, and orlistat. Drugs approved for treating obesity usually result in an additional weight loss of approximately 2$5 \mathrm{~kg}$ over placebo. At least four other types of single-agent weight loss drugs are in possible late stage development: (1) selective central cannabinoid-1 receptor blockers, (2) selective central 5-hydroxytryptamine $2 \mathrm{C}$ serotonin receptor agonists, (3) an intestinal lipase blocker, and (4) centralacting incretin mimetic drugs [85]. Furthermore, other agents under development that may produce beneficial changes in appetite expression in the obese include glucagonlike peptide-1 analogs such as liraglutide, an amylin analog davalintide, the $5-\mathrm{HT}_{(2 \mathrm{C})}$ receptor agonist lorcaserin, the monoamine re-uptake inhibitor tesofensine, and a number of combination therapies such as pramlintide and metreleptin, bupropion and naltrexone, phentermine and topiramate, and bupropion and zonisamide [86]. For example, lorcaserin is a selective agonist of the $5-\mathrm{HT}_{2 \mathrm{C}}$ serotonin receptor. Its shared mechanism of action with fenfluramine suggests that a lorcaserin-phentermine combination therapy may be particularly effective for treatment of obesity. The combination of naltrexone and bupropion has recently been examined in a large phase 3 trial for the treatment of obesity. This study demonstrated that one year of treatment with this two-drug combination produced an approximate $4 \%$ weight loss beyond that seen with placebo therapy, similar to that seen with other pharmacologic therapies. Because of the distinct mechanism of action of these two medications, naltrexone-bupropion may prove to be an attractive option for patients who are resistant to other agents. Several clinicians have noted that the combination of phentermine and topiramate can generate substantial weight loss in at least a subset of patients who exhibit little weight loss when treated with phentermine alone. These observations led to the development of fixed dose combinations of phentermine and topiramate. A large, phase 3 clinical trial has shown that one year of treatment with this combination led to weight loss of up to $9 \%$ beyond that seen with placebo therapy. There have been no head-to-head comparisons, however, and further studies will be needed to determine the relative effectiveness of these various treatments. It is noteworthy that the doses of each agent used in the phentermine topiramate combination studied were lower than the typical doses used for monotherapy with each drug [87]. In one study, following a 1-week placebo lead-in, 244 obese or overweight, nondiabetic subjects received placebo subcutaneously (sc) t.i.d., pramlintide sc $(120 \mu \mathrm{g}$ t.i.d. $)$, pramlintide sc $(120 \mu \mathrm{g}$ t.i.d.) + oral sibutramine (10 mg q.a.m.), or pramlintide sc $(120 \mu$ g t.i.d.) + oral phentermine (37.5 mg q.a.m.) for 24 weeks. Weight loss achieved at week 24 with either combination treatment was greater than with pramlintide alone or placebo [88]. As weight gain is often substantial with psychotropics, combined antiobesity therapy in clinical practice is frequently needed. Psychiatrists are often clinically savvy using rational polypharmacy to achieve remission of the psychiatric disorder at hand, and perhaps may consider polypharmacy in severe cases of psychotropic drug-induced obesity. Although risk benefits ratio for the use of single or multiple antiobesity agents needs to be determined on a case by case basis before the initiation of these therapies. Sometimes clinicians can "chase their tails" by adding antiside-effect medications to a patient's regimen. Sometimes the anti-side-effect medications have side effects themselves that must be treated, and so on. Clinicians must make critical, Hippocratic decisions when it comes to this complex clinical polypharmacy decision.

Single sympathomimetic amphetamine agents, because of their high potential for abuse, cardiac, and psychiatric side effects (anxiety induction, insomnia), are generally not often recommended for treating obesity [84]. Sibutramine is however relatively safer, as it is a mixed serotonergic and noradrenergic reuptake inhibitor. It helps patients achieve a $10 \%$ to $15 \%$ loss of body weight [89-92]. The safety and effectiveness beyond 1 year of use have not been determined. The mechanism by which sibutramine acts is increased satiety. It decreases the levels of triglycerides, total cholesterol, and LDL cholesterol, while also increasing the levels of HDL cholesterol (seen in people who lose $>5 \%$ of body weight). Sibutramine can increase blood pressure and heart rate. Other common adverse effects of sibutramine are dry mouth, anorexia, insomnia, irritability, and constipation. These studies were conducted in obese individuals who were not taking psychotropics, so the outcome may not be generalizable to the mentally ill. This agent when combined 
TABLE 1: Weight gain treatment options.

\begin{tabular}{llc}
\hline Mode or medication & Weight loss produced & Duration of treatment \\
\hline Behaviour modification & $0.5-0.7 \mathrm{~kg}$ per week & - \\
Cognitive-behavioral therapy & 4.5 drop in BMI & - \\
Naltreoxone and buropion & $4 \%$ & - \\
Phentermine and topiramate & $9 \%$ & $<1$ year \\
Sibutramine & $10-15 \%$ & 1 year \\
Orlistat & $10.2 \%, 8.8 \%$ & 2 years \\
Orlistat & $>10 \%$ & $?$ \\
Orlistat & $34.6 \%$ & $3-6$ months \\
Amantadine & $3.5 \mathrm{~kg}$ & 16 weeks \\
Nizatidine & Gained $3 \mathrm{~kg}$ less than patients who did not take Nizatidine & 8 weeks \\
Naltexone & $5 \mathrm{~kg}$ & - \\
Topiramate augmentation & $10-15 \mathrm{lbs}$ & 12 weeks \\
Metformin & $15 / 19$ patients lost weight &
\end{tabular}

with other antidepressants may lead to serotonin syndrome and is often avoided.

Case 2: Part 2. SK had only a partial improvement on the MAOI treatment, and subsequently, it was stopped but her weight gain was not alleviated. She was ultimately treated with a complex polypharmacy antidepressant regimen with near remission of her symptoms. Similar to Case 1, she was given metformin and orlistat with gradual, but not complete weight loss. To gain final remission of depression symptoms she was placed on a stimulant (methylphenidate) medication which was titrated to a moderate dose. Her depression resolved and she continued to lose weight to her baseline level.

Orlistat, a fat or lipase blocker, has safety and efficacy data for use, up to two years. Orlistat may be a better option than sibutramine for patients already taking other drugs because it does not act systemically, so there is less risk of interaction with centrally acting medications. Specifically, it inhibits gastric and pancreatic lipases by binding covalently to the serine residue at the active site of these enzymes [89]. This allows fat not to be absorbed by the GI system when taken with meals [90-92]. It decreases triglycerides, total cholesterol, and low-density lipoprotein cholesterol while increasing high-density lipoprotein cholesterol [93]. The drug also improves glycemic control [94]. The most common adverse effects are gastrointestinal, including increased defecation, soft stools, anal leakage, fatty or oily stools, and vitamin A and E deficiencies [95, 96]. Patients take orlistat $120 \mathrm{mg}$ three times daily and must take a multivitamin to avoid deficiencies and eat a low-fat diet.

Two large placebo-controlled trials $[97,98]$ document the efficacy of orlistat use for up to two years. After one year, the orlistat group lost $10.2 \%$ of body weight in one study and $8.8 \%$ in the second study. After 2 years, twice as many patients taking orlistat maintained a weight loss of more than $10 \%$. Patients must take other medications one hour before or after orlistat to avoid change in absorption [99]. One study in the mentally ill reported that 13 consecutive patients with psychotropic-induced weight gain lost $34.6 \%$ of side effect weight gained [100]. Nine of the 13 subjects suffered from major depressive disorder and were taking serotonergic antidepressants. Patients were deemed obese with a body mass index (BMI) of $>30 \mathrm{~kg} / \mathrm{m}^{2}$. The average weight gain from psychotropics prior to orlistat initiation was $16.4 \mathrm{~kg}$. The average weight loss within this relatively short time period was $5.6 \mathrm{~kg}$ or $34.6 \%$ of the weight gained as a result of psychotropic drug use.

Amantadine was studied [101] in twelve patients who had already gained a mean of $7.3 \mathrm{~kg}$ during olanzapine treatment. Subjects were started on amantadine at $300 \mathrm{mg}$ per day. Results of the study showed an average weight loss of $3.5 \mathrm{~kg}$ over 3-6 months. No adverse effects were reported. Implementation of nizatidine (histamine- 2 receptor antagonist) was studied in a 16-week, randomized, double-blind, placebo-controlled study in schizophrenia patients. Dosed at $300 \mathrm{mg}$ twice per day, it allowed patients to gain an average of $2.5 \mathrm{~kg}$ compared with the $5.5 \mathrm{~kg}$ gained by patients treated without nizatidine [102]. Naltrexone, an opioid antagonist, at a dosage of $50 \mathrm{mg} /$ day, has been shown to decrease weight by reversing the observed hunger and craving for sweet, fatty foods caused by tricyclic antidepressants and lithium. Subjects reported decreased enjoyment ratings of food and also diminished subjective feelings of hunger. No adverse effects of opioid antagonism were seen regarding depressive symptoms. In another study, naltrexone was coadministered with antidepressants to eight female patients who had already gained more than $6 \mathrm{~kg}$. After eight weeks, weight gain was reversed in five patients, stopped in two patients, and attenuated in another. However, weight increased by $1.5 \pm 2.7 \mathrm{~kg}$ within 14 weeks after the drug was stopped. Of note, the mean weight loss was small compared to previous drug-induced weight gain.

Preliminary findings suggest that topiramate may serve as a dual purpose agent in the treatment of obese patients with affective disorders. In one case report [103], topiramate was administered to a 29-year-old male schizophrenic patient who had gained weight due to clozapine. Results showed 
a sustained weight loss for the first time with an improvement of psychotic symptoms. Additionally, topiramate add-on studies for bipolar disorder have shown 33\%-55\% of patients losing weight (10-15 lbs) [104, 105]. Side effects of fatigue, cognitive dulling, ataxia, glaucoma, oligohydrosis, and acidosis are reported at doses of $100-400 \mathrm{mg} /$ day. A recent review of studies using metformin and topiramate has shown more efficacy and fewer side effects with metformin [106].

Metformin holds promise as a treatment for weight gain in pediatric patients taking psychotropic medications. In a 12-week open label study [107] conducted on 19 patients (aged 10-18 years) who had gained over 10\% of their baseline weight while on antipsychotics, $500 \mathrm{mg}$ three times a day of metformin was given for 12 weeks in addition to psychotropics. The results of the study showed 15 patients lost weight, 3 gained weight, and one remained unchanged in weight. Sporadic diarrhea was noted in some patients that resolved with time. The results of the safety tests for lactic acidosis were unremarkable. A recent controlled study by the same group confirmed this open label finding [108].

\section{Conclusions}

This paper has reviewed the risks of and possible causes of psychotropic-induced obesity and concluded with some potential treatment options designed to help manage this side effect, while ideally maintaining patients on effective, psychotropic regimens. There are no FDA approved agents for reversing or preventing this iatrogenic weight gain, and all options reported above are therefore considered off-label at this time. Many studies are uncontrolled and of small scale, limiting our conclusions in the mentally ill population. A combination of diet, exercise, and medications would be the ideal approach for combating the weight gain seen in the mentally ill population, but we often find these patients unable to comply with rigorous diet and exercise regimens due to their psychiatric symptoms. Other strategies which may be useful, but need further randomized placebocontrolled studies include switching the psychotropic medication to one less likely to cause metabolic changes as well as addition of medications such as topiramate and metformin to help reduce the change which has occurred. It is important to note that, although the use of psychotropic medication has contributed to the increased incidence of metabolic effects in the mentally ill population, certain studies have shown that, at baseline, patients with severe and persistent illness have a higher prevalence of metabolic disorders. Another concern is the high likelihood that metabolic disorders are untreated in patients with schizophrenia, with particularly high rates of nontreatment for hypertension and dyslipidemia. There is a need for increased attention to basic monitoring and treatment of metabolic risk factors in this vulnerable and often underserved psychiatric population [109].

The authors would welcome future psychotropics devoid of weight gain potential and strongly suggest future, larger controlled studies focusing on weight reduction in this population using pharmacologic, nonpharmacologic, and combined strategies.

\section{References}

[1] D. B. Allison, J. L. Mentore, M. Heo et al., "Antipsychoticinduced weight gain: a comprehensive research synthesis," American Journal of Psychiatry, vol. 156, no. 11, pp. 16861696, 1999.

[2] P. S. Masand, "Weight gain associated with psychotropic drugs," Expert Opinion on Pharmacotherapy, vol. 1, no. 3, pp. 377-389, 2000.

[3] H. Pijl and A. E. Meinders, "Bodyweight change as an adverse effect of drug treatment: mechanisms and management," Drug Safety, vol. 14, no. 5, pp. 329-342, 1996.

[4] H. Nasrallah, "A review of the effect of atypical antipsychotics on weight," Psychoneuroendocrinology, vol. 28, no. 1, pp. 8396, 2003.

[5] M. Fava, "Weight gain and antidepressants," Journal of Clinical Psychiatry, vol. 61, no. 11, pp. 37-41, 2000.

[6] C. L. Carman, N. M. Leung, and A. H. Gnberman, "Weight gain in epileptic patients during treatment with valproic acid: a retrospective study," Canadian Journal of Neurological Sciences, vol. 24, no. 3, pp. 240-244, 1997.

[7] T. G. Cantu and J. S. Korek, "Monoamine oxidase inhibitors and weight gain," Drug Intelligence and Clinical Pharmacy, vol. 22, no. 10, pp. 755-759, 1988.

[8] R. H. Weisler, J. A. Johnston, C. G. Lineberry, B. Samara, R. J. Branconnier, and A. A. Billow, "Comparison of bupropion and trazodone for the treatment of major depression," Journal of Clinical Psychopharmacology, vol. 14, no. 3, pp. 170-179, 1994.

[9] K. N. Roy Chengappa, J. Levine, D. Rathore, H. Parepally, and R. Atzert, "Long-term effects of topiramate on bipolar mood instability, weight change and glycemic control: a case-series," European Psychiatry, vol. 16, no. 3, pp. 186-190, 2001.

[10] T. Wetterling, "Bodyweight gain with atypical antipsychotics: a comparative review," Drug Safety, vol. 24, no. 1, pp. 59-73, 2001.

[11] R. S. McIntyre, M. Cohen, J. Zhao, L. Alphs, T. A. Macek, and J. Panagides, "Asenapine in the treatment of acute mania in bipolar I disorder: a randomized, double-blind, placebocontrolled trial," Journal of Affective Disorders, vol. 122, no. 1-2, pp. 27-38, 2010.

[12] D. Bishara and D. Taylor, "Asenapine monotherapy in the acute treatment of both schizophrenia and bipolar I disorder," Neuropsychiatric Disease and Treatment, vol. 5, no. 1, pp. 483-490, 2009.

[13] R. S. McIntyre, M. Cohen, J. Zhao, L. Alphs, T. A. Macek, and J. Panagides, "Asenapine versus olanzapine in acute mania: a double-blind extension study," Bipolar Disorders, vol. 11, no. 8, pp. 815-826, 2009.

[14] P. J. Weiden, A. J. Cutler, M. H. Polymeropoulos, and C. D. Wolfgang, "Safety profile of iloperidone: a pooled analysis of 6-week acute-phase pivotal trials," Journal of Clinical Psychopharmacology, vol. 28, no. 7, pp. S12-S19, 2008.

[15] E. Spina and R. Cavallaro, "The pharmacology and safety of paliperidone extended-release in the treatment of schizophrenia," Expert Opinion on Drug Safety, vol. 6, no. 6, pp. 651-662, 2007.

[16] H. Y. Meltzer, W. V. Bobo, I. F. Nuamah et al., "Efficacy and tolerability of oral paliperidone extended-release tablets in the treatment of acute schizophrenia: pooled data from 
three 6-week, placebo-controlled studies," Journal of Clinical Psychiatry, vol. 69, no. 5, pp. 817-829, 2008.

[17] S. Cohen, R. Glazewski, S. Khan, and A. Khan, "Weight gain with risperidone among patients with mental retardation: effect of calorie restriction," Journal of Clinical Psychiatry, vol. 62, no. 2, pp. 114-116, 2001.

[18] J. M. Russell and J. A. Mackell, "Bodyweight gain associated with atypical antipsychotics: epidemiology and therapeutic implications," CNS Drugs, vol. 15, no. 7, pp. 537-551, 2001.

[19] R. Ganguli, J. S. Brar, and Z. Ayrton, "Weight gain over 4 months in schizophrenia patients: a comparison of olanzapine and risperidone," Schizophrenia Research, vol. 49, no. 3, pp. 261-267, 2001.

[20] Y. Barak, "No weight gain among elderly schizophrenia patients after 1 year of risperidone treatment," Journal of Clinical Psychiatry, vol. 63, no. 2, pp. 117-119, 2002.

[21] D. M. Taylor and R. McAskill, "Atypical antipsychotics and weight gain-a systematic review," Acta Psychiatrica Scandinavica, vol. 101, no. 6, pp. 416-432, 2000.

[22] Y. Vanina, A. Podolskaya, K. Sedky et al., "Body weight changes associated with psycopharmacology," Psychiatric Services, vol. 53, no. 7, pp. 842-847, 2002.

[23] S. J. Kingsbury, M. Fayek, D. Trufasiu, J. Zada, and G. M. Simpson, "The apparent effects of ziprasidone on plasma lipids and glucose," Journal of Clinical Psychiatry, vol. 62, no. 5, pp. 347-349, 2001.

[24] P. E. Keck, M. Versiani, S. Potkin, S. A. West, E. Giller, and K. Ice, "Ziprasidone in the treatment of acute bipolar mania: a three-week, placebo-controlled, double-blind, randomized trial," American Journal of Psychiatry, vol. 160, no. 4, pp. 741748, 2003.

[25] S. Cohen, B. Fitzgerald, A. Okos, S. Khan, and A. Khan, "Weight, lipids, glucose, and behavioral measures with ziprasidone treatment in a population with mental retardation," Journal of Clinical Psychiatry, vol. 64, no. 1, pp. 60-62, 2003.

[26] M. Arato, R. O’Connor, and H. Y. Meltzer, "A 1-year, doubleblind, placebo-controlled trial of ziprasidone 40, 80 and 160 $\mathrm{mg}$ /day in chronic schizophrenia: the Ziprasidone Extended Use in Schizophrenia (ZEUS) study," International Clinical Psychopharmacology, vol. 17, no. 5, pp. 207-215, 2002.

[27] J. A. Frazier, J. Biederman, M. Tohen et al., "A prospective open-label treatment trial of olanzapine monotherapy in children and adolescents with bipolar disorder," Journal of Child and Adolescent Psychopharmacology, vol. 11, no. 3, pp. 239-250, 2001.

[28] K. H. Littrell, R. G. Petty, N. M. Hilligoss, C. D. Peabody, and C. G. Johnson, "Weight loss associated with olanzapine treatment," Journal of Clinical Psychopharmacology, vol. 22, no. 4, pp. 436-437, 2002.

[29] B. Søholm and H. Lublin, "Long-term effectiveness of risperidone and olanzapine in resistant or intolerant schizophrenic patients. A mirror study," Acta Psychiatrica Scandinavica, vol. 107, no. 5, pp. 344-350, 2003.

[30] J. A. Lieberman, G. Tollefson, M. Tohen et al., "Comparative efficacy and safety of atypical and conventional antipsychotic drugs in first-episode psychosis: a randomized, double-blind trial of olanzapine versus haloperidol," American Journal of Psychiatry, vol. 160, no. 8, pp. 1396-1404, 2003.

[31] G. Ratzoni, D. Gothelf, A. Brand-Gothelf et al., "Weight gain associated with olanzapine and risperidone in adolescent patients: a comparative prospective study," Journal of the American Academy of Child and Adolescent Psychiatry, vol. 41, no. 3, pp. 337-343, 2002.
[32] D. Gothelf, B. Falk, P. Singer et al., "Weight gain associated with increased food intake and low habitual activity levels in male adolescent schizophrenic inpatients treated with olanzapine," American Journal of Psychiatry, vol. 159, no. 6, pp. 1055-1057, 2002.

[33] J. A. Shaw, J. E. Lewis, S. Pascal et al., "A study of quetiapine: efficacy and tolerability in psychotic adolescents," Journal of Child and Adolescent Psychopharmacology, vol. 11, no. 4, pp. 415-424, 2001.

[34] M. Brecher, I. W. Rak, K. Melvin, and A. M. Jones, "The long-term effect of quetiapine (Seroquel ${ }^{\mathrm{TM}}$ ) monotherapy on weight in patients with schizophrenia," International Journal of Psychiatry in Clinical Practice, vol. 4, no. 4, pp. 287-291, 2000.

[35] D. Briffa and T. Meehan, "Weight changes during clozapine treatment," Australian and New Zealand Journal of Psychiatry, vol. 32, no. 5, pp. 718-721, 1998.

[36] C. J. Hong, C. H. Lin, W. Y. Yu Younger, K. H. Yang, and S. J. Tsai, "Genetic variants of the serotonin system and weight change during clozapine treatment," Pharmacogenetics, vol. 11, no. 3, pp. 265-268, 2001.

[37] G. Masi, M. Mucci, and S. Millepiedi, "Clozapine in adolescent inpatients with acute mania," Journal of Child and Adolescent Psychopharmacology, vol. 12, no. 2, pp. 93-99, 2002.

[38] D. B. Allison, J. L. Mentore, M. Heo et al., "Antipsychoticinduced weight gain: a comprehensive research synthesis," American Journal of Psychiatry, vol. 156, no. 11, pp. 16861696, 1999.

[39] J. S. Lamberti, T. Bellnier, and S. B. Schwarzkopf, "Weight gain among schizophrenic patients treated with clozapine," American Journal of Psychiatry, vol. 149, no. 5, pp. 689-690, 1992.

[40] S. G. Potkin, A. R. Saha, M. J. Kujawa et al., "Aripiprazole, an antipsychotic with a novel mechanism of action, and risperidone vs placebo in patients with schizophrenia and schizoaffective disorder," Archives of General Psychiatry, vol. 60, no. 7, pp. 681-690, 2003.

[41] H. I. Kaplan and B. J. Sadock, Synopsis of Psychiatry, Williams \& Wilkins, Baltimore, Md, USA, 8th edition, 1998.

[42] E. Frank, D. J. Kupfer, C. M. Bulik, and J. A. Levenson, "Imipramine and weight gain during the treatment of recurrent depression," Journal of Affective Disorders, vol. 20, no. 3, pp. 165-172, 1990.

[43] J. B. Prince, T. E. Wilens, J. Biederman et al., "A controlled study of nortriptyline in children and adolescents with attention deficit hyperactivity disorder," Journal of Child and Adolescent Psychopharmacology, vol. 10, no. 3, pp. 193-204, 2000.

[44] C. F. Paradis, J. A. Stack, C. J. George et al., "Nortriptyline and weight change in depressed patients over 60," Journal of Clinical Psychopharmacology, vol. 12, no. 4, pp. 246-250, 1992.

[45] M. Trivedi and A. Rush, "A review of randomized controlled medication trials in major depression," Biological Psychiatry, vol. 31, pp. 188-189, 1992.

[46] G. Chouinard, "Bupropion and amitriptyline in the treatment of depressed patients," Journal of Clinical Psychiatry, vol. 44, no. 5, pp. 121-129, 1983.

[47] J. W. Anderson, F. L. Greenway, K. Fujioka, K. M. Gadde, J. McKenney, and P. M. O’Neil, "Bupropion SR enhances weight loss: a 48-week double-blind, placebo-controlled trial," Obesity Research, vol. 10, no. 7, pp. 633-641, 2002. 
[48] E. Leinonen, J. Skarstein, K. Behnke, H. Ågren, and J. Th. Helsdingen, "Efficacy and tolerability of mirtazapine versus citalopram: a double-blind, randomized study in patients with major depressive disorder," International Clinical Psychopharmacology, vol. 14, no. 6, pp. 329-337, 1999.

[49] D. Michelson, J. D. Amsterdam, F. M. Quitkin et al., "Changes in weight during a 1-year trial of fluoxetine," American Journal of Psychiatry, vol. 156, no. 8, pp. 1170-1176, 1999.

[50] C. D. Bouwer and B. H. Harvey, "Phasic craving for carbohydrate observed with citalopram," International Clinical Psychopharmacology, vol. 11, no. 4, pp. 273-278, 1996.

[51] C. A. Abell, D. L. Farquhar, S. M. Galloway, F. Steven, A. E. Philip, and J. F. Munro, "Placebo controlled doubleblind trial of fluvoxamine maleate in the obese," Journal of Psychosomatic Research, vol. 30, no. 2, pp. 143-146, 1986.

[52] C. A. L. Moon and D. K. Jesinger, "The effects of psychomotor performance of fluvoxamine versus mianserin in depressed patients in general practice," British Journal of Clinical Practice, vol. 45, no. 4, pp. 259-262, 1991.

[53] M. Tohen, R. W. Baker, L. L. Altshuler et al., "Olanzapine versus divalproex in the treatment of acute mania," American Journal of Psychiatry, vol. 159, no. 6, pp. 1011-1017, 2002.

[54] B. H. Harvey and C. D. Bouwer, "Neuropharmacology of paradoxic weight gain with selective serotonin reuptake inhibitors," Clinical Neuropharmacology, vol. 23, no. 2, pp. 90-97, 2000.

[55] L. Ribeiro, J. V. Busnello, M. Kauer-Sant'Anna et al., "Mirtazapine versus fluoxetine in the treatment of panic disorder," Brazilian Journal of Medical and Biological Research, vol. 34, no. 10, pp. 1303-1307, 2001.

[56] O. Benkert, A. Szegedi, and R. Kohnen, "Mirtazapine compared with paroxetine in major depression," Journal of Clinical Psychiatry, vol. 61, no. 9, pp. 656-663, 2000.

[57] E. Stip and V. Tourjman, "Aripiprazole in schizophrenia and schizoaffective disorder: a review," Clinical Therapeutics, vol. 32, no. 1, pp. S3-S20, 2010.

[58] T. A. Pigott, A. Prakash, L. M. Arnold, S. T. Aaronson, C. H. Mallinckrodt, and M. M. Wohlreich, "Duloxetine versus escitalopram and placebo: an 8-month, double-blind trial in patients with major depressive disorder," Current Medical Research and Opinion, vol. 23, no. 6, pp. 1303-1318, 2007.

[59] K. N. R. Chengappa, L. Chalasani, J. S. Brar, H. Parepally, P. Houck, and J. Levine, "Changes in body weight and body mass index among psychiatric patients receiving lithium, valproate, or topiramate: an open-label, nonrandomized chart review," Clinical Therapeutics, vol. 24, no. 10, pp. 15761584, 2002.

[60] V. Biton, W. Mirza, G. Montouris, A. Vuong, A. E. Hammer, and P. S. Barrett, "Weight change associated with valproate and lamotrigine monotherapy in patients with epilepsy," Neurology, vol. 56, no. 2, pp. 172-177, 2001.

[61] Ginsberg et al., in Proceedings of the 156th Annual Meeting of the American Psychiatric Association, San Francisco, Calif, USA, May 2003.

[62] Y. Lampl, Y. Eshel, A. Rapaport, and I. Sarova-Pinhas, "Weight gain, increased appetite, and excessive food intake induced by carbamazepine," Clinical Neuropharmacology, vol. 14, no. 3, pp. 251-255, 1991.

[63] G. Luef, I. Abraham, M. Haslinger et al., "Polycystic ovaries, obesity and insulin resistance in women with epilepsy: a comparative study of carbamazepine and valproic acid in 105 women," Journal of Neurology, vol. 249, no. 7, pp. 835-841, 2002.
[64] T. Baptista, L. Teneud, Q. Contreras et al., "Lithium and body weight gain," Pharmacopsychiatry, vol. 28, no. 2, pp. 35-44, 1995.

[65] D. Gothelf, B. Falk, P. Singer et al., "Weight gain associated with increased food intake and low habitual activity levels in male adolescent schizophrenic inpatients treated with olanzapine," American Journal of Psychiatry, vol. 159, no. 6, pp. 1055-1057, 2002.

[66] D. B. Allison and D. E. Casey, "Antipsychotic-induced weight gain: a review of the literature," Journal of Clinical Psychiatry, vol. 62, no. 7, pp. 22-31, 2001.

[67] T. Kobayashi, K. Ikeda, and T. Kumanishi, "Effects of clozapine on the $\delta$ - and $\kappa$-opioid receptors and the Gprotein-activated $\mathrm{K}+(\mathrm{GIRK})$ channel expressed in Xenopus oocytes," British Journal of Pharmacology, vol. 123, no. 3, pp. 421-426, 1998.

[68] G. Curzon, E. L. Gibson, and A. O. Oluyomi, "Appetite suppression by commonly used drugs depends on 5-HT receptors but not on 5-HT availability," Trends in Pharmacological Sciences, vol. 18, no. 1, pp. 21-25, 1997.

[69] A. D. Strosberg and F. Pietri-Rouxel, "Function and regulation of the $\beta 3$-adrenoceptor," Trends in Pharmacological Sciences, vol. 17, no. 10, pp. 373-381, 1996.

[70] G. M. Goodwin, "How do antidepressants affect serotonin receptors? The role of serotonin receptors in the therapeutic and side effect profile of the SSRIs," Journal of Clinical Psychiatry, vol. 57, no. 4, pp. 9-13, 1996.

[71] S. H. Stahl, Essential Psychopharmacology, Cambridge University Press, New York, NY, USA, 1996.

[72] N. G. Clark, "Consensus development conference on antipsychotic drugs and obesity and diabetes," Diabetes Care, vol. 27, no. 2, pp. 596-601, 2004.

[73] D. Weiss, "How to help your patients lose weight: current therapy for obesity," Cleveland Clinic Journal of Medicine, vol. 67, no. 10, pp. 739-754, 2000.

[74] P. R. Thomas, Ed., Weighing the Options: Criteria for Evaluating Weight Management Programs, National Academy Press, Washington, DC, USA, 1995.

[75] S. M. Hannum, L. Carson, E. M. Evans et al., "Use of portioncontrolled entrees enhances weight loss in women," Obesity Research, vol. 12, no. 3, pp. 538-546, 2004.

[76] D. Umbricht, H. Flury, and R. Bridler, "Cognitive behavior therapy for weight gain," American Journal of Psychiatry, vol. 158, no. 6, pp. 971-972, 2001.

[77] H. M. Connolly, J. L. Crary, M. D. McGoon et al., "Valvular heart disease associated with fenfluramine phentermine," New England Journal of Medicine, vol. 337, no. 9, pp. 581588, 1997.

[78] K. P. Kelly and D. S. Kirschenbaum, "Immersion treatment of childhood and adolescent obesity: the first review of a promising intervention," Obesity Reviews, vol. 12, no. 1, pp. 37-49, 2011.

[79] M. Q. Werrij, A. Jansen, S. Mulkens, H. J. Elgersma, A. J. H. A. Ament, and H. J. Hospers, "Adding cognitive therapy to dietetic treatment is associated with less relapse in obesity," Journal of Psychosomatic Research, vol. 67, no. 4, pp. 315-324, 2009.

[80] R. B. Saper, D. M. Eisenberg, and R. S. Phillips, "Common dietary supplements for weight loss," American Family Physician, vol. 70, no. 9, pp. 1731-1738, 2004.

[81] M. H. Pittler and E. Ernst, "Dietary supplements for bodyweight reduction: a systematic review," American Journal of Clinical Nutrition, vol. 79, no. 4, pp. 529-536, 2004. 
[82] J. R. T. Davidson, K. Abraham, K. M. Connor, and M. N. McLeod, "Effectiveness of chromium in atypical depression: a placebo-controlled trial," Biological Psychiatry, vol. 53, no. 3, pp. 261-264, 2003.

[83] J. P. Docherty, D. A. Sack, M. Roffman, M. Finch, and J. R. Komorowski, "A double-blind, placebo-controlled, exploratory trial of chromium picolinate in atypical depression: effect on carbohydrate craving," Journal of Psychiatric Practice, vol. 11, no. 5, pp. 302-314, 2005.

[84] G. A. Bray, "Use and abuse of appetite-suppressant drugs in the treatment of obesity," Annals of Internal Medicine, vol. 119, no. 7, pp. 707-713, 1993.

[85] D. C. Klonoff and F. Greenway, "Drugs in the pipeline for the obesity market," Journal of Diabetes Science and Technology, vol. 2, no. 5, pp. 913-918, 2008.

[86] J. C. G. Halford, E. J. Boyland, J. E. Blundell, T. C. Kirkham, and J. A. Harrold, "Pharmacological management of appetite expression in obesity," Nature Reviews Endocrinology, vol. 6, no. 5, pp. 255-269, 2010.

[87] L. M. Kaplan, "Pharmacologic therapies for obesity," Gastroenterology Clinics of North America, vol. 39, no. 1, pp. 6979, 2010.

[88] L. J. Aronne, A. E. Halseth, C. M. Burns, S. Miller, and L. Z. Shen, "Enhanced weight loss following coadministration of pramlintide with sibutramine or phentermine in a multicenter trial," Obesity, vol. 18, no. 9, pp. 1739-1746, 2010.

[89] G. A. Bray, D. H. Ryan, D. Gordon, S. Heidingsfelder, F. Cerise, and K. Wilson, "A double-blind randomized placebocontrolled trial of sibutramine," Obesity Research, vol. 4, no. 3, pp. 263-270, 1996.

[90] M. E. J. Lean, "Sibutramine - a review of clinical efficacy," International Journal of Obesity, vol. 21, no. 1, pp. S30-S36, 1997.

[91] M. Weintraub, A. Rubio, A. Golik, L. Byrne, and M. L. Scheinbaum, "Sibutramine in weight control: a doseranging, efficacy study," Clinical Pharmacology and Therapeutics, vol. 50, no. 3, pp. 330-337, 1991.

[92] M. J. Stock, "Sibutramine: a review of the pharmacology of a novel anti-obesity agent," International Journal of Obesity, vol. 21, supplement 1, pp. S25-S29, 1997.

[93] R. Guerciolini, "Mode of action of orlistat," International Journal of Obesity, vol. 21, supplement 3, pp. S12-S23, 1997.

[94] L. F. van Gaal, J. I. Broom, G. Enzi, and H. Toplak, "Efficacy and tolerability of orlistat in the treatment of obesity: a 6-month dose-ranging study," European Journal of Clinical Pharmacology, vol. 54, no. 2, pp. 125-132, 1998.

[95] L. Sjöström, A. Rissanen, T. Andersen et al., "Randomised placebo-controlled trial of orlistat for weight loss and prevention of weight regain in obese patients," Lancet, vol. 352, no. 9123, pp. 167-172, 1998.

[96] W. McNeely, P. Benfield, L. Drent, and F. X. Pi-Sunyer, “Orlistat," Drugs, vol. 56, no. 2, pp. 241-250, 1998.

[97] P. A. Hollander, S. C. Elbein, I. B. Hirsch et al., "Role of orlistat in the treatment of obese patients with type 2 diabetes: a 1-year randomized double-blind study," Diabetes Care, vol. 21, no. 8, pp. 1288-1294, 1998.

[98] J. Zhi, A. T. Melia, S. G. Koss-Twardy, S. Arora, and I. H. Patel, "The effect of orlistat, an inhibitor of dietary fat absorption, on the pharmacokinetics of $\beta$-carotene in healthy volunteers," Journal of Clinical Pharmacology, vol. 36, no. 2, pp. 152-159, 1996.

[99] A. T. Melia, S. G. Koss-Twardy, and J. Zhi, "The effect of orlistat, an inhibitor of dietary fat absorption, on the absorption of vitamins A and E in healthy volunteers," Journal of Clinical Pharmacology, vol. 36, no. 7, pp. 647-653, 1996.

[100] T. L. Schwartz and M. Beale, "Psychotropic induced weight gain alleviated with orlistat," Psychopharm Bulletin, vol. 37, no. 1, pp. 5-8, 2003.

[101] M. Floris, J. Lejeune, and W. Deberdt, "Effect of amantadine on weight gain during olanzapine treatment," European Neuropsychopharmacology, vol. 11, no. 2, pp. 181-182, 2001.

[102] A. Breier, Y. Tanaka, and S. Roychowdhury, "Nizatidine for the prevention of weight gain during olanzapine treatment in schizophrenia and related disorders: a randomised controlled double-blind study," in Proceedings of the Meeting of the Colleges of Psychiatric and Neurologic Pharmacists, San Antonio, Tex, USA, March 2001.

[103] M. C. Lessig, N. A. Shapira, and T. K. Murphy, "Topiramate for reversing atypical antipsychotic weight gain," Journal of the American Academy of Child and Adolescent Psychiatry, vol. 40, no. 12, article 1364, 2001.

[104] S. N. Ghaemi, S. G. Manwani, J. J. Katzow, J. Y. Ko, and F. K. Goodwin, "Topiramate treatment of bipolar spectrum disorders: a retrospective chart review," Annals of Clinical Psychiatry, vol. 13, no. 4, pp. 185-189, 2001.

[105] E. Vieta, C. Torrent, G. Garcia-Ribas et al., "Use of topiramate in treatment-resistant bipolar spectrum disorders," Journal of Clinical Psychopharmacology, vol. 22, no. 4, pp. 431-435, 2002.

[106] L. K. Ellinger, H. J. Ipema, and J. M. Stachnik, "Efficacy of metformin and topiramate in prevention and treatment of second-generation antipsychotic-induced weight gain," Annals of Pharmacotherapy, vol. 44, no. 4, pp. 668-679, 2010.

[107] J. A. Morrison, E. M. Cottingham, and B. A. Barton, "Metformin for weight loss in pediatric patients taking psychotropic drugs," American Journal of Psychiatry, vol. 159, no. 4, pp. 655-657, 2002.

[108] D. J. Klein, E. M. Cottingham, M. Sorter, B. A. Barton, and J. A. Morrison, "A randomized, double-blind, placebocontrolled trial of metformin treatment of weight gain associated with initiation of atypical antipsychotic therapy in children and adolescents," American Journal of Psychiatry, vol. 163, no. 12, pp. 2072-2079, 2006.

[109] H. A. Nasrallah, J. M. Meyer, D. C. Goff et al., "Low rates of treatment for hypertension, dyslipidemia and diabetes in schizophrenia: data from the CATIE schizophrenia trial sample at baseline," Schizophrenia Research, vol. 86, no. 1-3, pp. 15-22, 2006. 


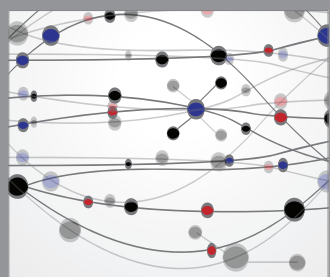

The Scientific World Journal
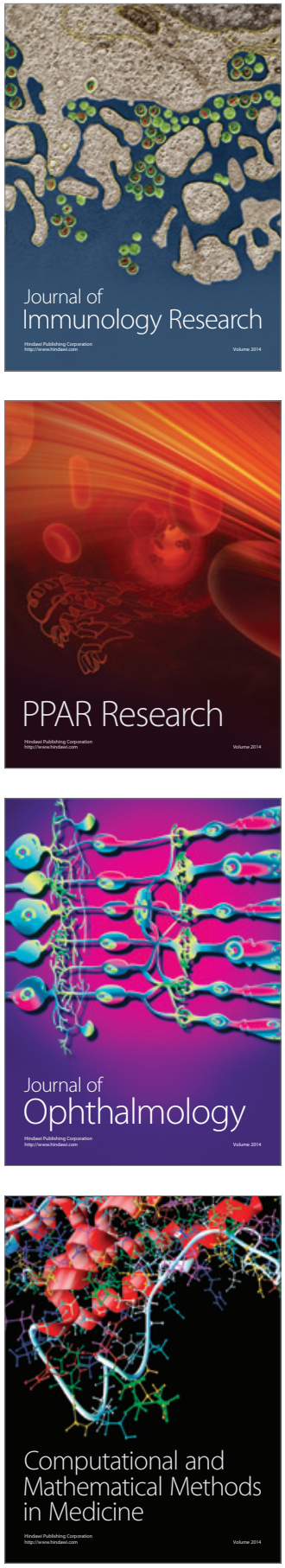

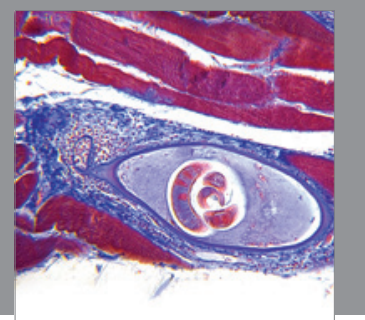

Gastroenterology

Research and Practice
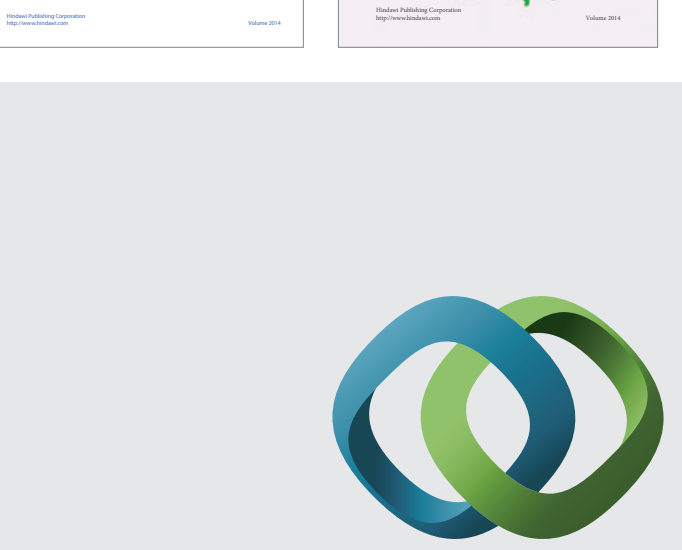

\section{Hindawi}

Submit your manuscripts at

http://www.hindawi.com
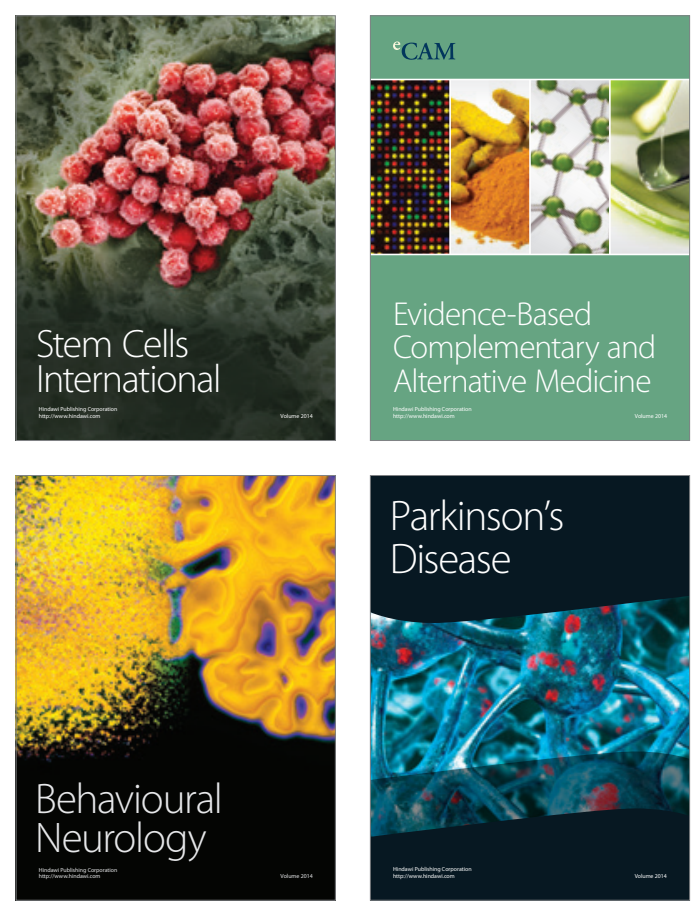

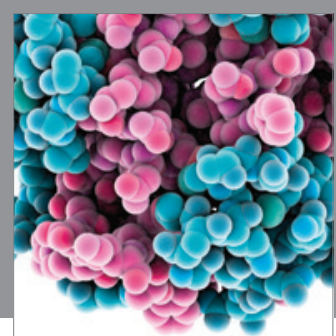

Journal of
Diabetes Research

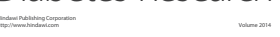

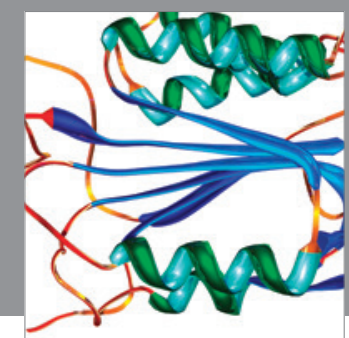

Disease Markers
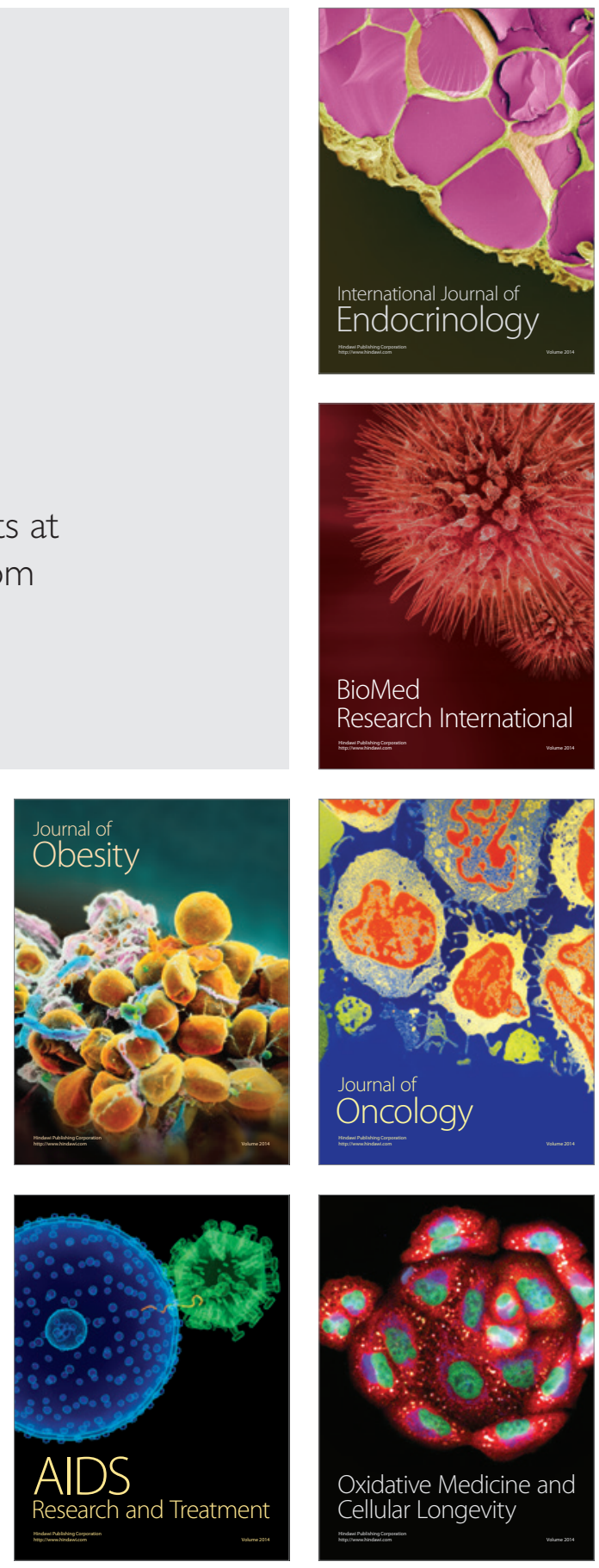